\title{
EXPERIMENTANDO O DESIGN NA GESTÃO PÚBLICA: O CASO DO LABORATÓRIO DE INOVAÇÃO DO ESTADO DO RIO DE JANEIRO
}

\section{EXPEREMENTING DESIGN IN PUBLIC MANAGEMENT: THE CASE OF THE RIO DE JANEIRO SATE INNOVATION LAB}

\author{
Enzo Mayer Tessarolo, D.Sc ${ }^{1}$. \\ enzotessarolo@gmail.com \\ Camila da Silva, Bach. ${ }^{1}$ \\ camilamoreira@gmail.com \\ Artur Rangel, Bach. \\ artur.kja@gmail.com \\ Diogo Coelho, Bach. ${ }^{1}$ \\ dicoelho@casacivil.rj.gov.br \\ Isadora Bittencourt Hertz Bach. ${ }^{1}$
} isahertz@gmail.com

${ }^{1}$ Governo do Estado do Rio de Janeiro, Rio de Janeiro, Brasil

laboratórios de inovação; design; governança; capacidade estatal

Este artigo explora as interações entre design e gestão pública, com foco na atuação de um Laboratório de Inovação em Governo: o Laboratório de Aceleração da Eficiência Pública do Estado do Rio de Janeiro (LAEP). É uma pesquisa exploratória e descritiva, evidenciada no estudo de caso e na avaliação da implementação do LAEP e de seus projetos, sobretudo o Plano Estratégico 2025. O objetivo é explorar como o design pode provocar cooperação entre pessoas e agências públicas e transformar a cultura governamental. Argumenta-se que a experimentação do design na gestão pública pode aumentar a capacidade estatal de enfrentar problemas complexos e gerar impactos positivos nas organizações e na sociedade.

Innovation labs; design; governance; state capacity

This article explores the interactions between design and public management, based on the practice of design within the Laboratory of Acceleration of Public Efficiency in the State of Rio de Janeiro (LAEP). It is an exploratory and descriptive research, evidenced in the case study of the implementation process of the State Strategic Plan 2025, from the point of view of public managers, designers and political scientists. The goal is to analyze how design can provoke cooperation between people and public agencies and transform government culture. It is argued that the practice of design and public management is complementary, and it can increase the state's capacity to face complex problems and generate positive impacts. 


\section{Introdução: o design em contextos de alto conflito e ambiguidade na gestão pública}

O objetivo deste artigo é contribuir para a literatura sobre design e gestão pública, a partir do estudo de caso da implementação do LAEP, Laboratório de Aceleração da Eficiência Pública do Estado do Rio de Janeiro. Trata-se de pesquisa exploratória, escrita pela própria equipe do Laboratório em momento de avaliação de resultados e transição política no Governo, no segundo semestre de 2020.

No Brasil, enquanto este artigo é escrito, estamos enfrentando o novo coronavírus, mudanças climáticas, crises econômicas, desemprego, pobreza, miséria. Estamos entre os 10 países mais desiguais do mundo. Seis brasileiros concentram a mesma riqueza de 100 milhões de brasileiros (EL PAÍS, 2019). Uma concentração de renda no $1 \%$ mais rico que existe há séculos e persiste mesmo após a redemocratização, em 1985 (SOUZA, 2016).

No estado do Rio de Janeiro, vivemos mais intensamente as crises políticas, econômicas, sociais e morais que o País sente. O colapso da aliança entre PMDB e PT e a prisão de cinco ex-governadores por escândalos de corrupção gerou desconfiança e um vazio político ocupado temporariamente por líderes à direita, guardiões da bandeira de combate ao crime (ESTADÃO, 2020).

É um contexto altamente conflituoso e ambíguo, o que inviabiliza ou dificulta muito a implementação de políticas públicas. De acordo com teorias da ciência política, governantes podem manipular variáveis de conflito e ambiguidade no ciclo de gestão pública. Quando querem que uma política seja executada, negociam recursos e editam leis, diminuindo a ambigüidade e o conflito. Por outro lado, podem retirar recursos ou criar conflitos que não existem, aumentando a complexidade e diminuindo a capacidade de execução de uma política (LOTTA, 2019).

Diante desse cenário, como o design e laboratórios de inovação podem estimular a cooperação na implementação de projetos e políticas públicas? Como o design pode tornar a complexidade parte do processo de planejamento governamental? Como o design pode provocar mudanças culturais no serviço público, estimulando o trabalho colaborativo e a participação da sociedade na resolução de problemas complexos? Essas são algumas das perguntas orientadoras desta pesquisa.

Nossa hipótese é que o uso do design por Laboratórios de Inovação em Governo aumenta a cooperação intergovernamental e tornam o Estado mais conectado às demandas da sociedade, por que adotam metodologias centradas nos usuários de serviços e políticas públicas. Outra hipótese é que os Laboratórios contribuem para orientar políticas públicas para os desafios de desenvolvimento sustentável da Agenda 2030 da Organização das Nações Unidas.

Essas suposições estão embasadas na literatura e na observação participante dos autores deste artigo. Estamos alinhados ao argumento de que ambientes de inovação adotam arranjos de governança constituídos por diversas agências e atores políticos orientados para o enfrentamento de problemas complexos (TONURIST; KATTEL; LEMBER, 2017). Os Laboratórios de Inovação têm como premissa o foco no usuário de serviços públicos, a empatia e a experimentação na cocriação de soluções centrados no ser humano, além de adaptarem o processo de formulação de políticas públicas ao contexto e recursos disponíveis (CAVALCANTE; MENDONÇA; BRANDALISE, 2019).

Para testar essas hipóteses, primeiro o artigo introduz conceitos-chave e contextualiza o processo de emergência dos Laboratórios de Inovação em Governo, trazendo à tona o uso do design na gestão pública. Em seguida, analisamos a implementação do Laboratório de Aceleração da Eficiência Pública (LAEP) no Estado do Rio, como caso representativo do uso do design para enfrentar problemas complexos e fortalecer a cultura de inovação no setor público. Ferramentas, relatórios e dados oficiais são apresentados para analisar o potencial e os desafios de Laboratórios de Inovação em Governo. 


\section{Design, Laboratórios de Inovação e capacidades estatais para enfrentar problemas complexos}

Para situar o debate sobre as relações entre design e gestão pública, cabe alinhar alguns conceitos, já que este artigo aborda múltiplos campos de conhecimento, principalmente Design, Ciência Política, Administração Pública, Antropologia e Sociologia. Nesta seção, conceituamos o que a literatura chama de problemas complexos, capacidade estatal, cooperação intergovernamental, inovação e laboratórios de inovação.

O uso do design no setor público é reflexo de mudanças globais nas relações entre Estado, Sociedade e Mercado, a partir da segunda metade do século XX. Demandas sociais cada vez mais dinâmicas e interdependentes colocaram em cheque o papel do Estado, desafiando o poder de governar. É nesse contexto de problemas complexos (RITTEL; WEBBER, 1973) que os governos foram pressionados a inovar, favorecendo a adoção de novas tecnologias de gestão pública e a criação de ambientes de inovação.

De acordo com Bason $(2013 ; 2021)$, os Laboratórios de Inovação surgiram no setor público como resposta aos problemas complexos da sociedade, às restrições fiscais e às reformas no Estado de bem-estar. Eles inauguraram novas abordagens de planejar e gerir a coisa pública, criando ambientes seguros para experimentar novas abordagens centradas no usuário de serviços públicos. Nesse movimento, o Design Thinking trouxe para o contexto da política pública uma abordagem prática, agregando o pensamento criativo ao analítico, valorizando a busca da construção coletiva de soluções (CAVALCANTE, MENDONÇA; BRANDALISE, 2018).

É nesse período de reformas do Estado, na década de 80, que Peter Evans, Rueschemeyer e Theda Skocpol (1985, p. 9) revisam o papel do Estado e apresentam o conceito de capacidade estatal como a "capacidade de implementar as metas governamentais, especialmente considerando a oposição concreta ou potencial de grupos sociais poderosos ou de circunstâncias econômicas adversas". Nessa lógica, a capacidade estatal está associada à capacidade de formar alianças entre atores centrais do processo decisório: políticos, burocratas de médio e alto escalão (LOTTA, 2019), atores das comunidades de políticas públicas. O alcance das metas governamentais depende de quanto esses atores estão dispostos a cooperar na implementação de políticas públicas, entendidas como um "fluxo de decisões públicas, orientado a manter o equilíbrio social ou a introduzir desequilíbrios destinados a modificar essa realidade" (SARAIVA, 2007, p. 28).

A implementação é um processo político marcado por conflitos de ideias e recursos na agenda pública. Logo, quanto mais atores envolvidos, mais difícil é viabilizar a coordenação de políticas públicas e a cooperação intergovernamental. Em sistemas federativos democráticos, isso implica em estabelecer acordos entre diversas agências ou entes, por meio de arranjos institucionais que induzam a coordenação e a cooperação. A cooperação intergovernamental diz respeito à dinâmica de interação entre os atores envolvidos na implementação da política pública. Pode ser observada em iniciativas com planejamentos e recursos compartilhados entre agências, na existência de sistemas e canais de comunicação integrados, em grupos de trabalhos formados por profissionais com competências e habilidades variadas (TESSAROLO, 2018).

A cooperação intergovernamental é uma dimensão da capacidade estatal observável em "procedimentos de inclusão dos múltiplos atores de forma articulada nos processos de políticas públicas, visando à construção de consensos mínimos e coalizões de suporte aos planos, programas e projetos governamentais" (GOMIDE; PIRES, 2014). Em arranjos institucionais de implementação de políticas públicas no Brasil, a cooperação intergovernamental costuma aparecer no formato de Comitês, Conselhos, Redes de Trabalho, Comunidades de Prática, Coordenações Intersetoriais. E, nos últimos anos, os Laboratórios de Inovação têm impulsionado essa forma de trabalho colaborativo. É o que sustentamos neste artigo e em trabalhos anteriores (MOREIRA, TESSAROLO, 2020).

Nessa dimensão político-relacional da capacidade estatal, argumentamos que o Design provoca mudanças institucionais na forma como as políticas públicas são produzidas. Evidências (SORENSEN, 2012; TESSAROLO, MOZINE, 2012; BASON, 2017) sugerem que soluções desenhadas junto com a população 
são melhores para enfrentar problemas locais. Essa é uma mudança radical na forma de formular e produzir políticas públicas, tradicionalmente conduzidas por departamentos separados em silos ou ilhas governamentais (CHRISTIANSEN; BUNT, 2014).

Os Laboratórios de Inovação adicionam dinamismo e transversalidade à estrutura da Administração Pública. Eles operam como espaços colaborativos de cocriação de soluções, fomentam arranjos organizacionais e uma governança orientada para enfrentar problemas complexos. Funcionam, assim, como ativos da inovação, já que a colaboração pode estimular a inovação pública (ANSELL, TORFING, 2014; SORENSEN , TORFING, 2012; BASON, 2017).

Conforme Relatório do Observatório da OCDE (2017), inovar é implementar uma transformação que seja nova no seu contexto e que gere valor público. No contexto do setor público, a experimentação do design é uma tendência que contribui para explorar inovações no ciclo de políticas públicas. Afinal, "o design como disciplina é também confortável com complexidade e incerteza, sendo, portanto, normalmente usado como método de inovação - como modo de antecipação de futuro de estado ainda inimaginável e intangível" (BASON, 2014, p. 229).

As experiências pioneiras de uso de design na gestão pública são creditadas a países nórdicos e anglo-saxões. Dinamarca, Reino Unido e Estados Unidos começaram a aplicar design thinking na formulação de políticas públicas e no enfrentamento de problemas públicos, a partir da década de 70 (Sorensen e Torfing, 2012). A partir dos anos 2000, essa tendência se expandiu para a América Latina, onde surgiram ambientes de inovação como o Laboratório de Inovação Pública de Santa Fé (SANTALAB, 2017), na Argentina, o Laboratório Nacional de Inovação Pública, na Costa Rica, o LABCapital de Bogotá (2016), Colômbia, e o Laboratório de Gobierno, no Chile (2015).

De acordo com Ferreira e Botero (2020), os Laboratórios de Inovação na América Latina foram alavancados por forças tecnológicas, pressões pela digitalização de serviços e processos públicos mais eficientes. A desconfiança dos cidadãos em relação aos governos também contribuiu para tornar a agenda pública mais transparente e aberta à participação popular, tema central na atuação dos laboratórios latinos.

No Brasil, diversos governos subnacionais passaram a adotar abordagens de design para desenvolver planos, programas, projetos e políticas públicas, a partir de 2010. No Plano Ceará 2050, por exemplo, o Governo usou ferramentas de design estratégico para definir objetivos, indicadores e metas em oficinas colaborativas com a população e servidores públicos. Conforme Plataforma Ceará 2050, usar o design em planejamentos governamentais é "mais adequado para ambientes dinâmicos e dotados de algum grau de incerteza, aleatoriedade e contradições. Uma proposta de Plano integralmente de fora para dentro a partir da compreensão real das necessidades de públicos beneficiários".

No Governo do Estado do Espírito Santo, a equipe do Laboratório de Inovação (LabGes) realizou diversas oficinas de solução de problemas, usando métodos colaborativos inspirados em abordagens de design thinking, design centrado no humano. Uma das iniciativas desenvolvidas para fortalecer a cultura de inovação no setor público foi o Tsunami de Design Thinking, uma capacitação para todos servidores de uma Secretaria estadual, para integrar pessoas e alinhar conhecimentos sobre o uso do design no órgão (CALIMAN; ASSIS, 2019).

De acordo com Sano (2020), em 2020 existem no Brasil mais de 43 Laboratórios de Inovação no setor público. Para ser classificado como tal, é preciso "ser um ambiente colaborativo, que busca fomentar a criatividade, a experimentação e a inovação, por meio de metodologias ativas de cocriação na resolução de problemas". Os objetivos dos laboratórios de inovação reúnem: fomento de um ambiente inovador na administração pública; desenvolvimento de inovações e modernização de processos; criação de novos mecanismos de participação do cidadão. Nas próximas seções do artigo, vamos explorar a dinâmica de trabalho e os desafios de implementação de um Laboratório presente no estudo de Sano, o LAEP. 


\section{LAEP, um Laboratório de Inovação que explora o Design no Governo}

O Laboratório de Aceleração da Eficiência Pública (LAEP) foi fundado oficialmente em fevereiro de 2019 (Decreto 46.591/2019), e extinto em setembro de 2020 (Decreto $n^{\circ} 42.278 / 2020$ ). O Laboratório surgiu em um momento de troca de governo e reestruturação administrativa no Estado do Rio de Janeiro. Ele nasceu da vontade da cúpula da então Secretaria de Estado da Casa Civil e Governança em difundir a abordagem do Design Thinking no setor público estadual, em resposta a pressões por processos mais eficientes.

De janeiro a março de 2019, a equipe do Laboratório foi inicialmente formada por sete profissionais: três oriundos do mercado especialistas em inovação e marketing, três servidores da carreira estadual de Especialistas em Políticas Públicas e Gestão Governamental, e um economista servidor de carreira da Companhia Estadual de Águas e Esgotos Rio de Janeiro. Em abril, a equipe mudou de perfil, com a saída de dois servidores públicos e a chegada de dois especialistas em design estratégico, design gráfico e experiência do usuário. Tornou-se mais diversa, com mais uma mulher e um homem negro.

A equipe iniciou os trabalhos em uma sala pequena no segundo andar do prédio anexo do Palácio Guanabara. Mas logo identificou uma oportunidade de ocupar a ante-sala do auditório do Palácio. Era um local estrategicamente localizado, na sede do Governo, com espaço para receber pessoas e interagir em oficinas de design. $\mathrm{O}$ espaço funcionou como uma vitrine para projetos inovadores, contribuindo para inspirar pessoas a adotarem novas metodologias no trabalho. $\mathrm{O}$ mobiliário e os equipamentos de informática foram adquiridos por doação do depósito público do Estado, ou aproveitados de salas do próprio prédio anexo. Ao longo do tempo, foram feitas reformas para aumentar a acessibilidade no local para pessoas com deficiência, com a instalação, por exemplo, de corrimãos.

A equipe amadureceu seu escopo de atuação, a partir de benchmarking e entrevistas realizadas com outros Laboratórios de Inovação no Brasil e no Mundo, especialmente em São Paulo, Minas Gerais e Espírito Santo. Representantes do LAEP também participaram do Encontro Internacional de Inovação em São Paulo, em julho de 2019 (WERNECK, 2020), para modelar o Laboratório considerando as necessidades do Governo do Estado do Rio de Janeiro. Como resultado, a partir de setembro de 2019, o LAEP passou a ter duas frentes de atuação: reenquadrar problemas complexos e fomentar a cultura de inovação no setor público fluminense.

Em 2020, a dinâmica de trabalho no Laboratório envolvia 05 macroprocessos: explorar tendências, metodologias, estratégias, evidências de políticas públicas e iniciativas inovadoras; capacitar servidores públicos; acelerar soluções inovadoras no Estado para o desenvolvimento sustentável; desenvolver soluções inovadoras; disseminar a comunicação de práticas inovadoras.

As demandas eram recebidas por diferentes públicos e canais. O LAEP recebia demandas estratégicas do Governador e do Vice Governador, do Secretário da Casa Civil, de Subsecretários da Casa Civil; demandas de formulação de políticas públicas e estruturas de governança da Subsecretaria Geral da Casa Civil; demandas de servidores públicos por capacitações em métodos ágeis e design; demanda de servidores públicos por aceleração de eficiência pública (modelagem de estratégias, modelagem de projetos, pesquisas, panoramas, melhorias em processos); demandas de atores do ecossistema de inovação por desenvolvimento de soluções inovadoras para problemas públicos.

As entregas do Laboratório geralmente estavam relacionadas a: planejamento e design estratégico; servidores capacitados em temas de inovação, design thinking e gestão pública; melhorias em projetos, processos e serviços; formação de redes colaborativas de trabalho; soluções inovadoras e protótipos de soluções. Em quase dois anos de existência, o Laboratório executou 20 projetos, e recebeu o $3^{\circ}$ lugar no Prêmio Nacional de Inovação Pública organizado pela Rede Conexão Inovação. Parte dos resultados pode ser acompanhado no Plano Plurianual 2020-2023 do Estado, na ação "Design de Serviços e Soluções para o Fortalecimento do Setor Público Fluminense". 
Comparado a outros laboratórios de inovação mapeados no estudo de Hironobu Sano (2020), o LAEP era um laboratório "desenvolvedor de soluções" e "criador de inovação"; "Facilitador"; "Educador"; e "Disseminador". Em termos de escopo de atuação, assemelha-se ao LABGes (do Governo do Estado do Espírito Santo), ao IrisLab (do Governo do Estado do Ceará) e ao 011Lab (da Prefeitura de São Paulo).

Semelhante aos laboratórios estudados por Sano (2020), o LAEP promovia eventos e encontros de inovação. No total, o LAEP capacitou mais de 700 pessoas, em 14 eventos de aprendizagem, com diferentes perfis de público: dirigentes do Estado, servidores estaduais, procuradores, controladores, gestores municipais, jovens, idosos, servidores de setores da saúde, turismo, educação, segurança, assistência social, ciência e tecnologia e Casa Civil, entidades da sociedade civil organizada, equipes e redes de inovação.

A equipe do LAEP utilizava uma trilha para facilitar os processos de inovação. A Trilha de Aceleração da Eficiência Pública foi inspirada em abordagens do Design adaptadas para o contexto da Administração Pública fluminense. Ela também explorava abordagens sistêmicas (SENGE, 1990), ciência comportamental (THALER; SUNSTEIN, 2019), e teorias de mudança (CLOUTIER, 2003; AMPLIFY CHANGE, 2020).

Esse método de ação seguia a ideia do Duplo Diamante do Design Thinking (DSCHOOL; DESIGN COUNCIL, 2020), e partia do entendimento de que processos de inovação e enfrentamento de problemas complexos ocorrem em etapas não lineares (BUIJS; SMULDER; MEER, 2009). Ainda mais no setor público, onde é preciso realizar frequentemente atividades de alinhamento político e leitura de contextos para gerir projetos. Dada a especificidade do trabalho no setor público, o método de trabalho do LAEP entendia que processos de inovação pública são essencialmente políticos e sistêmicos, já que moldados por instituições e forças que se sobrepõem umas às outras na organização da sociedade. A dinâmica viva das interações sociais demanda do Design, na prática, processos mais fluidos. Assim pode-se aproveitar ao máximo o potencial criativo do ser humano. Eis a razão dos fluxos circulares de aceleração da eficiência pública, como ilustra a Figura 2.

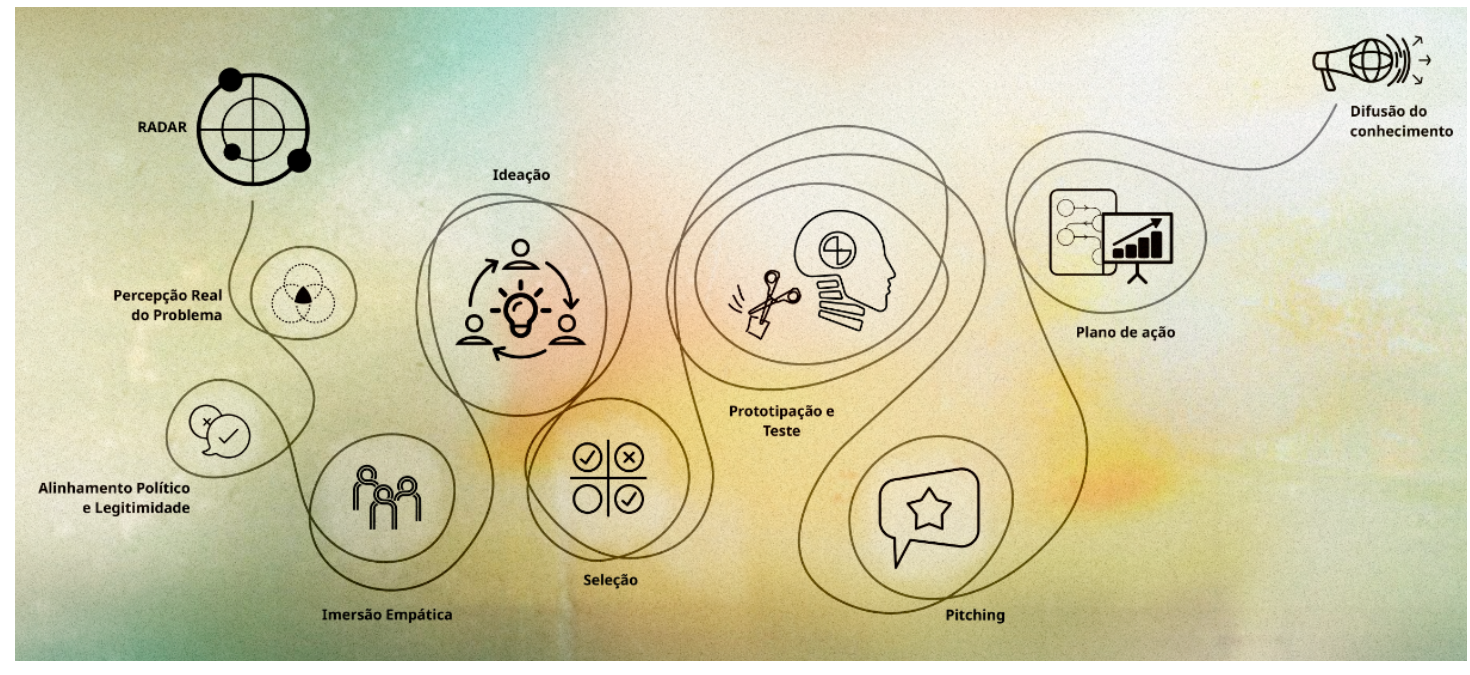

Figura 1 - Fluxo de Aceleração da Eficiência Pública

Fonte: Laboratório de Aceleração da Eficiência Pública, LAEP, 2020.

Para cada uma dessas etapas do processo, o LAEP experimentava diversas ferramentas, a depender do contexto e do problema a ser enfrentado. Para ilustrar algumas ferramentas de trabalho utilizadas nos projetos e processos de inovação, o LAEP usou: 
- Análise de Tendências: ferramenta de análise usada para mapear fatores que podem impactar positivamente ou negativamente o projeto, contribuindo para subsidiar a tomada de decisões. O modelo analítico proporciona uma visão sistêmica e parte da busca por oportunidades e ameaças tecnológicas, sociais, legais, institucionais, políticas, econômicas e ambientais. Essa ferramenta foi usada em uma Oficina do projeto de criação de um Hub de Governo, que contou com 7 participantes, dois da Controladoria Geral do Estado, três da Secretaria de Estado da Ciência, Tecnologia e Inovação, dois do LAEP. O projeto de estruturação do "HubGov" tinha o objetivo de tornar o Estado referência na resolução colaborativa de problemas públicos, com foco no cidadão e no desenvolvimento sustentável.
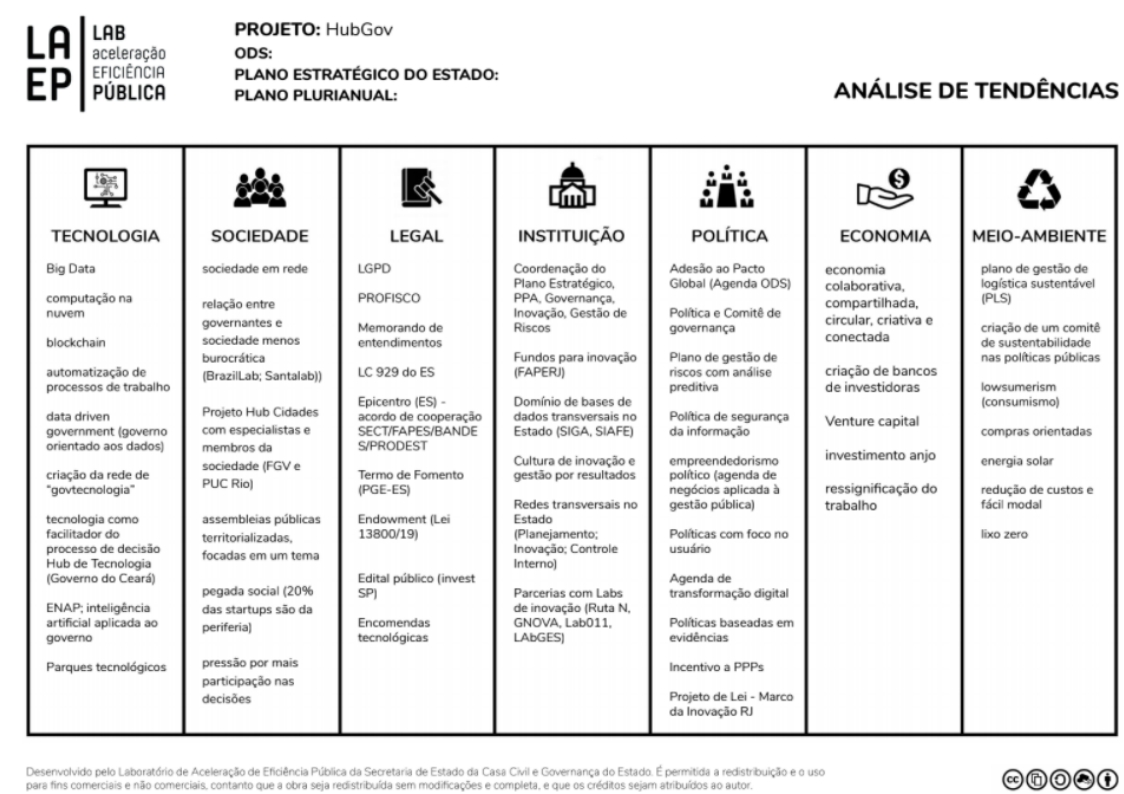

Figura 2 - Ferramenta de análise de tendências

- Starbursting ("estrelinha"): usada para modelar projetos, o "starbusting" é um ferramenta para gerar perguntas e explorar o potencial das ideias dos atores participantes. A exploração parte do desenho de uma grande estrela de seis pontas com os termos mais usados para construir frases interrogativas (Por que, Como, Onde, Quando, O que e Quem). E no meio da estrela consta o desafio, serviço ou produto a ser explorado pelo grupo. Essa ferramenta foi usada em vários projetos, entre eles o Plano Estadual de Inovação e Tecnologia Educacional, em fevereiro de 2020. Em uma Oficina com 10 participantes, sendo 07 da Secretaria de Estado da Educação, e 03 do LAEP. Também foi usada para desenhar o Plano de Governo Digital do Estado, em setembro de 2020, como ilustra a figura abaixo.

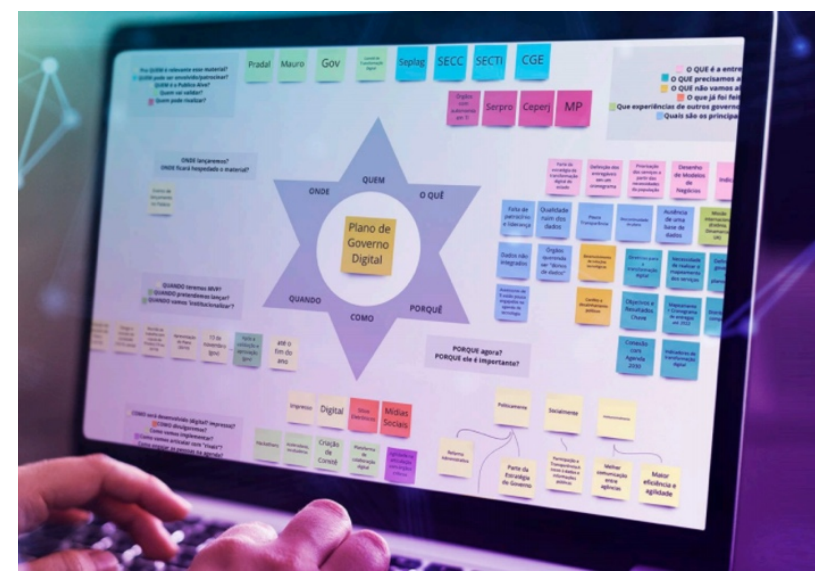

Figura 3 - Ferramenta "Starbursting" 
- Canvas de Políticas Públicas: ferramenta usada para estruturar projetos, de forma colaborativa. Ela serve para explorar o problema que se deseja alterar, dados e evidências que retratam a realidade, o público alvo da iniciativa, o impacto esperado, os parceiros e recursos envolvidos, formas de divulgação, a equipe responsável e pontos de atenção. Trata-se de adaptação do modelo de canvas tradicional para o contexto do serviço público. Foi usado para estruturar os projetos executados, dentre eles o "Prêmio Jovem Cidadão", cujo objetivo era incentivar jovens a se engajar no enfrentamento da Covid19 em seus territórios.

- Maratonas de Pesquisa ("Pesquisatona"): método de pesquisa desenvolvido pelo Inova_MPRJ e adaptado pelo LAEP para o Executivo estadual. Ele estimula a pesquisa e a inteligência coletiva, reunindo pessoas com diferentes experiências para pesquisar juntas por cerca de duas horas. A partir de perguntas geradoras, os grupos se dividem e vão ganhando pontos conforme avançam na pesquisa, em um ambiente de competição saudável. A ferramenta foi usada no projeto "Plano Estadual de Inovação e Tecnologia Educacional", cujo desafio era "como melhorar a qualidade do ensino na rede pública estadual?". A Oficina contou com 20 representantes da Secretaria de Estado da Educação, do Ministério Público, do Sebrae, da Fundação Ceperj e da Fundação João Goulart/NudgeRio (LAEP, 2020).

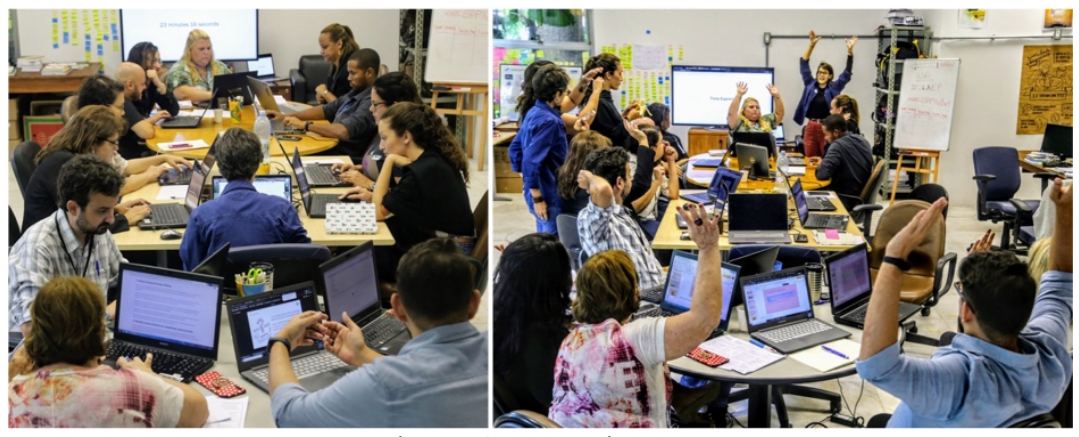

Figura 4 - Pesquisatona

Fonte: Laboratório de Aceleração da Eficiência Pública, LAEP, 2020.

- Pensamento Icônico (LAEP, 2020): ferramenta de ideação, na qual os participantes são convidados a pensar como um ícone da cultura pop, como Lady Gaga, Darth Vader e Sting. Em seguida, colocando-se no lugar dessa figura, cada um deve imaginar como resolveria o problema em questão. Para isso, são definidas três características relacionadas à personalidade selecionada, que servirão para idear soluções. Por fim, os insights de como resolver o problema são compartilhados com o grupo. A ferramenta foi usada, entre outros, no projeto "Soluções para a Saúde", que reuniu cerca de 25 gestores públicos, de cinco Secretarias distintas, para enfrentar o problema do atendimento primário em saúde no contexto da pandemia do novo coronavírus.

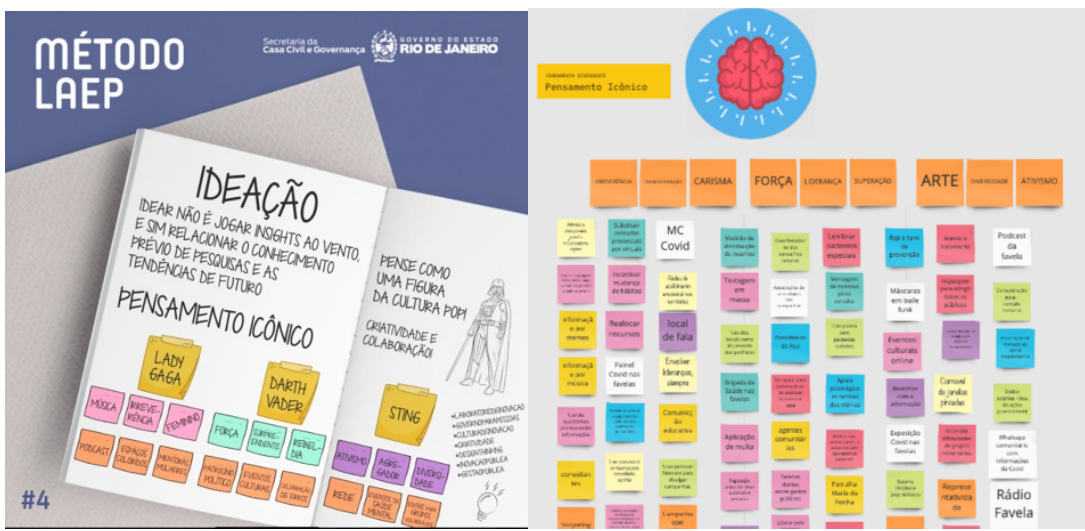

Figura 5 - Ferramenta Pensamento Icônico 
- Pontocracia e Matriz de Impacto e Viabilidade: ferramentas de seleção e priorização, usadas quando se tem grande quantidade de ideias geradas e pouco tempo para decidir. Uma votação simples ajuda a fazer uma curadoria prévia, ajudando a objetivar a seleção, considerando fatores de impacto (para o usuário e o patrocinador do projeto) e viabilidade de execução. A ferramenta foi usada nas Oficinas do Plano Estratégico 2025, a seguir detalhadas. E em uma Oficina do projeto "HackNit" da Prefeitura de Niterói, com cerca de 20 participantes divididos em grupos temáticos, para selecionar os desafios que seriam levados para a maratona de inovação de 2020.

- Encenação: ferramenta de prototipação e teste usada no projeto "Guia Presente", que combinava uma rede de guias presenciais em pontos turísticos e uma plataforma digital. Após as fases de imersão, ideação e definição, a equipe de 15 pessoas da Secretaria de Estado de Turismo encenou o uso do protótipo desenvolvido para enfrentar o problema "como atrair turistas para o Estado?". A intenção da ferramenta é alimentar a coragem coletiva e explorar a perspectiva o usuário na tomada de decisão sobre o protótipo. No desenvolvimento do protótipo, as equipes visitaram pontos turísticos e entrevistaram 55 turistas na Confeitaria Colombo e no Museu do Amanhã, por exemplo.

- "Pitching": é uma apresentação rápida, de 1 a 5 minutos, feita para despertar o interesse de parceiros e patrocinadores no modelo de negócios, ideia ou protótipo desenvolvido ao longo de um processo de inovação. É o momento de validação, constituía a fase final da Trilha de Aceleração da Eficiência Pública. No projeto "Guia Presente", os 02 protótipos desenvolvidos foram apresentados pela equipe para uma banca de patrocinadores, com os então titulares das Secretarias da Casa Civil e do Turismo.

Para aprofundar a análise sobre o potencial e os desafios de implementação de um Laboratório de Inovação em Governo, bem como da experimentação do design na gestão pública, a seguir fazemos um estudo de caso do principal projeto executado pelo LAEP, o Plano Estratégico 2025 do Estado do Rio de Janeiro. Trata-se de projeto proprietário do Laboratório, que envolveu todas as Secretarias de Estado, com patrocínio da cúpula do Governo.

\section{A experimentação do design no Planejamento Estratégico 2025}

Sobre o quadro de implementação do Plano Estratégico 2025, os usuários do projeto eram dirigentes públicos responsáveis por estabelecer diretrizes prioritárias para o Governo. Entre eles, burocratas de médio e alto escalão no governo (Superintendentes, Subsecretários) e políticos responsáveis por tomar decisões estratégicas (Governador, Vice-Governador, Secretários de Estado e Presidentes de agências públicas).

A Secretaria de Estado da Casa Civil e Governança era a patrocinadora do projeto, enquanto agência responsável por coordenar programas, políticas e iniciativas públicas no Estado. À Casa Civil cabia conduzir a visão estratégica de longo prazo do Estado e harmonizar instrumentos formais de planejamento e orçamento, como o Plano Plurianual (PPA), a Lei de Diretrizes Orçamentárias (LDO) e a Lei Orçamentária Anual (LOA). A coordenação do Plano ficou sob responsabilidade do LAEP.

Um dos principais desafios do projeto era viabilizar a cooperação entre as mais de 30 agências públicas participantes da implementação do Plano Estratégico. Afinal, como construir estratégias transversais em uma estrutura administrativa departamental, segmentada em temas de políticas públicas, em um contexto de conflitos por recursos escassos e ambiguidades nas diretrizes? Como conduzir uma visão de futuro compartilhada para o Estado, com foco em problemas reais da população?

No caso do Plano Estratégico 2025, a abordagem inspirada no Design contribuiu para projetar cenários, captar prioridades e riscos em entrevistas com os dirigentes públicos, simplificar a compreensão de dados e evidências, abrir espaços de fala e escuta, e comunicar as diretrizes estratégicas do Governo. Usar o design no projeto foi também uma estratégia para melhorar as relações humanas, como será detalhado a seguir. 


\section{Alinhamento político}

Entendendo que a Inovação no setor público se concretiza quando alinhada às diretrizes prioritárias de governo, o LAEP realizou algumas atividades de alinhamento político entre março e abril de 2019. A equipe entrevistou dois patrocinadores do projeto para alinhar expectativas do projeto (escopo, tempo, custo), além de analisar o contexto, tendo como direcionador o Plano de Diretrizes do Governo e a Agenda 2030 da ONU.

Vale destacar que era um momento de crise no Estado, e novas lideranças chegavam à gestão do Executivo estadual, após um longo ciclo político encerrado no final de 2018. Parte da equipe do LAEP havia participado da transição de Governo, o que contribuiu para o alinhamento político e para ampliar visões sobre os projetos prioritários no Estado. $\mathrm{O}$ fato de a equipe contar com gestores públicos de carreira também ajudou a formar redes de trabalho e a captar necessidades de integração com instrumentos governamentais de planejamento e orçamento, como o Plano Plurianual (PPA).

A partir das entrevistas com os patrocinadores e da leitura de contexto, a equipe gestora decidiu realizar um planejamento ágil, para viabilizar a execução do plano no tempo solicitado (6 meses), e flexível para se adaptar às tendências do futuro. $O$ horizonte de tempo escolhido (5 anos, 2020 a 2025) foi mais curto do que o habitual em planejamentos estratégicos de governos, como estratégia de adaptação ao contexto político e econômico do Estado. Trata-se também de data histórica, que marca os 50 anos da fusão do Estado da Guanabara com o Estado do Rio de Janeiro, ocorrida em 1975

No processo de trabalho, buscou-se desde o início a conexão entre os diversos instrumentos de planejamento do Governo. No contexto de mudança completa de Governo, foi necessário que os desenvolvimentos do Plano Estratégico 2019-2025 e do Plano Plurianual 2020-2023 ocorressem concomitantemente. Houve um alinhamento constante entre os dois instrumentos, com reuniões periódicas entre as equipes responsáveis, de forma que eles partissem do mesmo diagnóstico e se construíssem em torno de um mesmo conceito basilar: a multisetorialidade de objetivos e programas, entendendo que os grandes problemas e desafios do estado só poderão ser superados através de ações integradas de órgãos e entidades da Administração Pública. Foi realizado um trabalho de correlacionamento entre os programas multissetoriais e ações de nível estratégico do PPA com, respectivamente, os objetivos multissetoriais e os resultados-chave do Plano Estratégico.

A comunidade de pessoas envolvidas na elaboração do Plano constituiu uma Rede de Planejamento Estratégico, com até 05 pessoas representantes de cada um dos 38 órgãos participantes. Na Rede participaram servidores da carreira de Especialistas em Políticas Públicas e Gestão Governamental lotados nas Secretarias de Estado, além de técnicos responsáveis pelo monitoramento do PPA e Assessores vinculados ao Gabinete dos Secretários. A equipe do LAEP decidiu por esse perfil na Rede de Planejamento Estratégico, com base na evidência (Silva, 2013) de que relações informais mantidas por servidores de carreira facilitam a cooperação intergovernamental, pois ampliam perspectivas de longo prazo na implementação de projetos e políticas públicas.

Foi realizada uma reunião de lançamento do projeto ("Kick Off”) no Auditório do Palácio Guanabara, em junho de 2019. Com o objetivo de alinhar os resultados esperados e obter patrocínios políticos, a equipe do LAEP apresentou a metodologia, o cronograma de trabalho e as funções de cada profissional da Rede de Planejamento Estratégico. Ao final da apresentação, os participantes foram conduzidos ao espaço do Laboratório de Inovação, para fortalecer o relacionamento e compartilhar desafios e visões de futuro. Foi uma oportunidade para que os servidores públicos se familiarizassem com novas ferramentas de trabalho, inclusive o Canvas de Entrevista usado para entrevistar Secretários de Estado e Governador, conforme detalhado na próxima sessão do artigo. 


\section{Imersão: narrativas de dados e entrevistas com usuários}

Após a fase de alinhamento político, o LAEP realizou pesquisas exploratórias, coletou dados sobre problemas públicos fluminenses, buscou informações em relatórios oficiais de governo, em mídias sociais, e conduziu entrevistas com usuários. Essas foram algumas das atividades na imersão, a seguir detalhados.

Os dados coletados foram analisados e compilados em um Panorama da situação atual do estado, sob o aspecto econômico, fiscal, demográfico, social e da segurança pública, com o apoio do Centro Estadual de Estatísticas, Pesquisas e Formação de Servidores Públicos do Rio de Janeiro (CEPERJ) e da Secretaria de Estado da Fazenda (SEFAZ). Esse Panorama é um documento com cerca de 30 páginas e os indicadores selecionados embasaram uma Análise SWOT, para mapear forças, fraquezas, oportunidades e ameaças, conforme tabela abaixo. O Panorama e a Análise SWOT subsidiaram as equipes participantes nas fases seguintes de ideação e definição.

\section{Lista de indicadores selecionados do Panorama do Estado para a Análise SWOT}

$42 \%$ dos municípios com aglomerados subnormais e $84,8 \%$ com loteamentos irregulares e/ou clandestinos

$2^{\mathrm{a}}$ maior taxa de desocupação do Brasil entre os estados (15,3\% $1^{\circ}$ tri 2019)

Alteração das regras para distribuição dos royalties podem gerar perda de $\mathrm{R} \$ 70$ bilhões nas receitas em 5 anos

Arrecadação do ICMS dependente de atividades com estruturas de mercado concentradas e com alíquotas elevadas

Nota do estado no ranking de competitividade dos estados da CLP em 2018 abaixo da média nacional

111 grandes investimentos confirmados para o RJ nos próximos anos (R $\$ 162$ bi em projetos)

Mais de $50 \%$ do PIB nacional em um raio de $500 \mathrm{~km}$ do Rio de Janeiro

Elevada taxa de distorção idade-série no Ensino Médio

ERJ não atingiu as metas nas últimas 3 edições do IDEB

$\%$ da Dívida Corrente Líquida sobre a Receita Corrente Líquida acima do limite legal da LRF $(270 \%$ × $200 \%)$

Posição do estado na Escala Brasil Transparente (26a posição, de 27)

Última posição no pilar "Solidez Fiscal" do Ranking de Competitividade dos Estados da CLP, em 2018

Estoque de restos a pagar de R \$ 18,8 bilhões, em 31/12/2018

Pressão popular por combate à corrupção

Intensificação de eventos climáticos que provocam calamidades públicas

Quantidade média anual de médicos no SUS por mil habitantes superior à média nacional e do Sudeste

Taxa de mortalidade materna é de 71 óbitos a cada 100 mil nascidos vivos, 3 vezes superior à recomendada pela OPAS

231,6 mil registros de roubo em 2018

6.714 vítimas de letalidade violenta em 2018

Entre 2007 e 2017, número de mulheres mortas por arma de fogo na residência cresceu $28,7 \%$

Investimentos em segurança decorrentes do Gabinete de Intervenção Federal

Apenas 4\% dos presos do ERJ trabalham, enquanto a média nacional é de 15\% em 2018

Tabela 1- Lista de indicadores e evidências selecionadas do Panorama do Estado.

Fontes: CEPERJ (2018, 2019); FIRJAN (2019); IBGE (2019); CLP (2018); SEFAZ (2018); ISP (2019).

A pesquisa exploratória foi apresentada também em "Narrativas", ferramenta criada pelo LAEP para contar histórias baseadas em problemas reais enfrentados pela sociedade fluminense. A narrativa teve a função de traduzir os dados coletados em contextos sobre como as pessoas se sentem e o que dizem quando enfrentam, por exemplo, horas de trânsito para trabalhar. A Narrativa tinha um título em formato manchete que facilitava a rápida consulta e a análise das equipes participantes das Oficinas, contribuindo para causar empatia e sensibilizá-las sobre a necessidade de formular soluções multissetoriais para enfrentar problemas complexos. Como ilustra a Figura abaixo. 


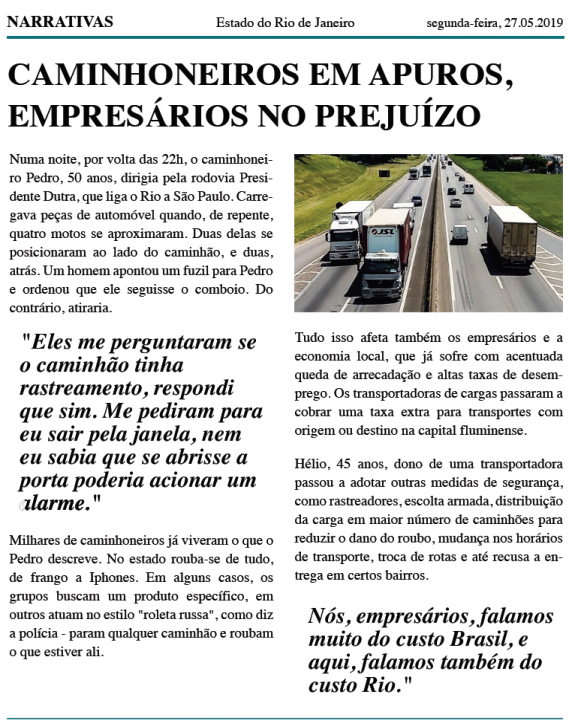

FATOS: Em 2017, foi registrado no estado, um roubo de cargas a cada 50 minutos.

R\$ 607,1 MI éa estimativa do prejuízo causados por roubos de carga à economia fluminense

0 roubo de cargas foi o principal delito que afetou as empresas industriais fluminenses em 2016 [Folha de Săo Paulo, ISP e FIPAAN]

Figura 6 - Narrativas

Ainda na fase de imersão, a equipe do Laboratório conduziu entrevistas com o Governador, o Vice-

Governador e todo o secretariado do governo. O modelo de entrevista inspirou-se em técnicas do Design e da Antropologia que mergulham na experiência dos usuários, por meio de perguntas abertas e escuta ativa. Após dois testes com patrocinadores do projeto, foram realizadas entrevistas olho-no-olho, nas salas de trabalho dos entrevistados. O LAEP se dividiu em duplas ou trios para conduzi-las, uma pessoa responsável pelas perguntas, e a outra por registrar os principais achados em um Canvas de Entrevista desenhado para a ocasião, conforme imagem abaixo. Os pontos-chave das entrevistas foram depois colocados em planilhas, para facilitar a análise e o compartilhamento das diretrizes com a Rede de Planejamento Estratégico.

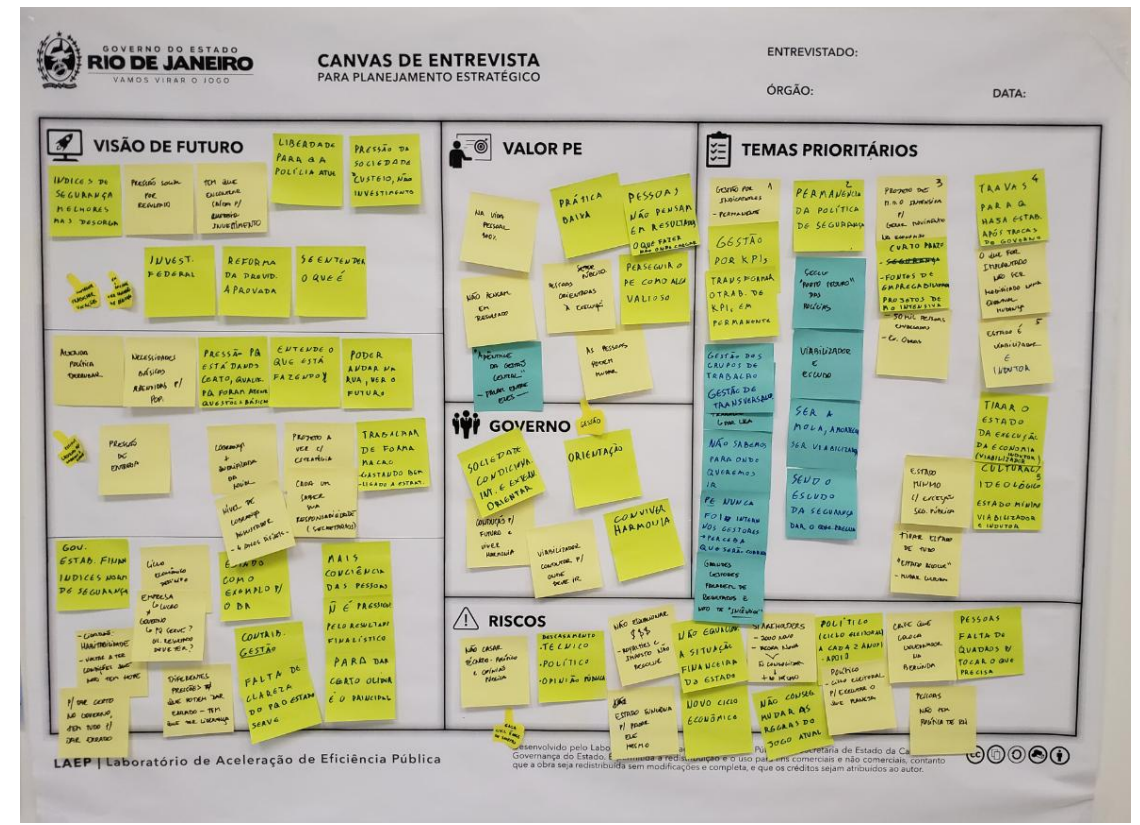

Figura 7 - Canvas de Entrevista 
As entrevistas duravam cerca de 1 hora e seguiam roteiro semi-estruturado, com 5 a 7 perguntas abertas. Iniciava-se com uma apresentação e entrega de materiais sobre o projeto e a metodologia, além de assinatura de um termo de confidencialidade para gravação das entrevistas. Em seguida, ocorria um aquecimento, em que o entrevistado era convidado a dizer em uma palavra "o que é governo para você" e "qual o valor de um Planejamento Estratégico para o Estado do Rio de Janeiro". Depois, a entrevista seguia para visões de futuro, onde se perguntava "Que Estado você quer em 2025, 2024, 2023, 2021, 2020". Em seguida, o entrevistado era provocado a ter visões pessimistas do futuro, como estratégia de mapeamento de riscos. Assim, perguntava-se "Imagine que você viajou para o futuro e descobriu que as iniciativas planejadas falharam, o Governo falhou... o que pode ter acontecido?". Por fim, o entrevistado era convidado a elencar até 05 temas prioritários para o Estado, considerando o contexto do órgão que representava. Nos minutos finais da entrevista era aberto espaço para a pessoa compartilhar o que quisesse.

No total, foram realizadas 25 entrevistas, com todos dirigentes máximos dos órgãos estaduais da administração direta, em maio de 2019. O Canvas de Entrevista serviu para obter patrocínio político, captar prioridades, riscos, visão de futuro e estratégias de integração e regionalização de políticas e serviços públicos. Além de sensibilizar os tomadores de decisão sobre a relevância de novas práticas de gestão, a ferramenta contribuiu para analisar padrões e oportunidades, realizar cruzamentos de informações e fornecer insumos para a próxima fase, de ideação.

\section{Ideação: em busca de diversidade e cooperação nas oficinas de planejamento estratégico}

A etapa de ideação do projeto consistiu na realização de Oficinas ("Workshops") de Planejamento Estratégico conduzidas pela equipe do LAEP para gerar colaboração entre servidores públicos e objetivos estratégicos. Participaram das Oficinas todas as Secretarias de Estado e alguns órgãos da administração indireta, envolvendo no total 38 agências públicas. Durante o mês de julho e agosto de 2019, foram realizadas 07 oficinas, seguindo a divisão temática proposta para organizar as equipes do Governo: Saúde (08/07/2019), Meio Ambiente (10/07), Infraestrutura, Transportes e Cidades (16/07), Desenvolvimento Humano (19/07), Desenvolvimento Econômico (24/07), Segurança (31/07), Gestão Pública (02/08).

Cerca de 150 servidores públicos participaram da dinâmica, como Presidentes e Vice Presidentes de entidades públicas, Subsecretários, Superintendentes e Assessores. Pessoas com diferentes perfis de idade, gênero e formação profissional. No alto escalão do Governo, porém, predominavam homens: dos 17 Subsecretários de Estado, 13 eram homens (76\%), assim como todos os três Presidentes de Fundação e três Chefes de Gabinete participantes. As mulheres ocupavam cargos de nível intermediário nas agências (Superintendentes, Diretorias), principalmente nas áreas de governo de Desenvolvimento Humano, Saúde e Meio Ambiente. No total, a Rede contou com 90 homens (62\%) e 56 mulheres (48\%). Mais da metade das pessoas (54\%) trabalhavam há menos de 01 ano no Estado, 16\% trabalhavam há mais de 10 anos, 15\% entre 5 e 9 anos, e $14 \%$ entre 2 e 4 anos.

Durante as Oficinas, que duravam cerca de 6 horas organizadas em 1 dia de trabalho, as equipes eram instigadas a se reconectar ao serviço público e à vontade de deixar um legado de vida. Com isso, o LAEP esperava guiar a produção de objetivos estratégicos alinhados aos Objetivos de Desenvolvimento Sustentável (ODS), parâmetro universal de ações de melhoria da qualidade de vida dos cidadãos, com permanência ao longo do tempo e respeito ao meio-ambiente.

As sessões ideativas se iniciavam com a revisão do material produzido nas etapas anteriores (Panorama, Análise SWOT, Narrativas, achados dos Canvas de Entrevista). A partir desse conteúdo, os participantes eram provocados a conversar em grupos pequenos (cerca de 5 a 7 pessoas) sobre como poderiam contribuir individualmente para a visão de futuro (2025) do Estado. Após esse brainstorming, os grupos trabalhavam colaborativamente para criar objetivos intersetoriais para a área de governo que representavam. 
A elaboração dos objetivos seguia a metodologia OKR (Objetivos e Resultados-Chave, na sigla em inglês). De acordo com a qual os objetivos devem ser inspiradores, gerar vontade de agir, e os resultados-chave devem ser mensuráveis. Essa metodologia foi escolhida por preconizar a simplicidade, a força na comunicação, a transparência, a integração entre equipes e o engajamento, fomentando uma cultura focada em inovação (DOERR, 2018).

Cada pessoa escrevia individualmente os objetivos para a área de governo e depois compartilhava com o grupo, que precisava chegar a um consenso sobre que objetivos seriam mantidos. Para agilizar o processo de tomada de decisão, foi usada uma Matriz de Impacto e Viabilidade, em que cada participante tinha 3 votos para distribuir entre as opções disponíveis. Assim, antes do almoço as equipes já tinham uma visão compartilhada dos Objetivos Estratégicos da área que representavam.

No período da tarde, ocorria a dinâmica de elaboração dos Resultados-Chave. Neste momento, ao invés de grupos formados por pessoas de agências diferentes, os grupos eram compostos por pessoas da mesma agência para fortalecer o senso de responsabilidade com os critérios de sucesso a serem perseguidos até 2025. Após uma sessão de brainstorming, as equipes definiam até 05 Resultados-Chave por objetivo, para induzir a coordenação posterior e o foco de trabalho.

No final, foi realizada uma pesquisa de avaliação da Oficina com 90 respostas obtidas. Entre as avaliações positivas recebidas, destacam-se aqueles sobre a relevância do conteúdo e da metodologia adotada (88\%), sobre oportunidades de integração $(84,5 \%)$ e sobre a dinâmica de construção de objetivos estratégicos $(83,5 \%)$. Alguns depoimentos ilustram a percepção dos participantes:

Achei super interessante e empolgante a metodologia utilizada! Parabéns. Além disso, se o LAEP puder criar mais momentos de integração, vou achar super válido! Estamos carentes de uma boa comunicação, integração, relacionamentos estratégicos... enfim, precisamos nos dar as mãos e seguir em frente! Obrigada, abraços pra vcs e mais uma vez PARABÉNS!

A iniciativa de um laboratório é valiosa e o empenho de vocês foi show. Importantíssima a integração e a articulação entre diferentes instrumentos de gestão. Obrigada

Parabéns pela inciativa, é inspirador saber que temos pessoas querendo fazer a diferença dentro do governo. Não estamos sozinhos. A sugestão é promover este encontro com mais secretarias com atividades comuns e mais representantes das autarquias vinculadas às nossas secretarias. Mas de qualquer forma parabéns a toda equipe pelo empenho e dedicação. Contem com a gente neste desafio.

Comentários construtivos e críticas também foram recebidos, sobretudo quanto a: infraestrutura do Laboratório e do prédio anexo do Palácio Guanabara; necessidade de treinamento prévio na metodologia OKR; apoio para aumentar a integração entre as Secretarias; ausência de participantes da alta gestão na Oficina por parte de alguns órgãos. Destacamos as seguintes sugestões de melhoria:

Acho que pode ficar para uma próxima oportunidade uma aproximação para estruturação conjunta de políticas em temáticas especificas, já que muitos resultados chaves mencionam sinergia entre Secretarias.

Ótima iniciativa, mas senti falta da presença de um condutor da alta gestão da Secretaria dentro do dia.

Local com melhor infra (ar condicionado, por exemplo). Importante verificar os banheiros, pois embora limpos, estavam com portas com dificuldades de tranca.

Acho que a parte de explicação sobre OKR poderia ser maior. Seria interessante comparar com outros modelos. Falta deixar mais claro como este dia se integrará com os trabalhos internos de planejamento estratégico e de PPA. De qualquer forma, acho o método excelente e as dinâmicas ótimas. Parabéns! 
Os retornos recebidos dos participantes serviram como aprendizado contínuo e fonte de adaptação das Oficinas seguintes. Após a primeira Oficina, a equipe do Laboratório passou a preparar mais exemplos práticos de redação de OKRs, usando como inspiração o Plano Estratégico do Distrito Federal, referência de utilização da metodologia em governos. Aumentou-se também o tempo de estudo para os materiais direcionadores (Panorama, Entrevistas) e para a dinâmica de elaboração dos resultados-chave. A importância da presença de representantes de nível estratégico nas Oficinas foi reforçada em ações de comunicação e grupos de whatsapp criados para cada uma das 7 áreas de governo.

A infraestrutura do Laboratório foi aperfeiçoada, com instalação de pontos de internet, cabeamento para computadores, corrimão na escada de acesso, mas o ar condicionado e os banheiros permaneceram um gargalo. Na arquitetura do prédio anexo do Palácio Guanabara, o Laboratório compartilhava paredes com um restaurante-escola, o que impedia a equipe de controlar o ar condicionado. O Laboratório também não tinha banheiro próprio, então os participantes em eventos usavam os banheiros de acesso público do Auditório ou do próprio prédio.

\section{Consolidação: desafios de continuidade para obter a validação do projeto}

O material produzido durante as Oficinas foi compilado pelo LAEP e enviado em agosto de 2019 para a Rede de Planejamento Estratégico. Os representantes das 07 áreas de governo receberam apoio do LAEP para padronizar e simplificar a linguagem do Plano, além de integrar ações entre Secretarias, aumentando a consistência metodológica e a coerência entre os Objetivos Estratégicos. Após reuniões individuais com as equipes das Secretarias, as autoridades máximas validaram as propostas de OKR em suas respectivas agências. No total, foram produzidos

A equipe do LAEP conduziu também uma consulta pública para escutar os desejos da sociedade, em setembro de 2019. A pesquisa foi inspirada na "Consulta Cidades Inteligentes", organizada pela ONUHabitat em cidades fluminenses. Adotou-se o método quantitativo e a escala Likert, com valores menores representando percepções negativas a temas do Plano Estratégico e valores positivos indicando percepções positivas. A consulta ficou aberta durante 5 dias e obteve 904 respostas $-45 \%$ veio de mulheres e $12 \%$ de pessoas com ensino fundamental ou médio. A mobilização foi feita pela própria equipe do Laboratório e por participantes da Rede de Planejamento Estratégico, sem comunicações oficiais de Governo.

A intenção da consulta pública não foi encontrar significância estatística, e sim superar vieses de representatividade do grupo de servidores e dirigentes públicos participantes do processo, além de inspirar a liderança do Governo a tomar decisões embasadas nas expectativas da sociedade. Comentários de cidadãos fluminenses foram inseridos no documento do Plano, em cada área de governo, como estes:

Penso que devemos ter uma rede de Saúde organizada com garantia do acesso independente da classe social. Proporcionar acesso precoce para tratamento das patologias e evitar o agravamento e sua cronicidade.

O Governo do Estado precisa quebrar a roda que alimenta a miséria e a criminalidade. Só educação e ações voltadas para os jovens de comunidades carentes podem fazer isso.

O transporte público é muito caro para uma condução que mal tem assento, demora muito, não tem ar condicionado, as portas não funcionam e tem assaltos constantes.

Na fase de consolidação do Plano, entre setembro e outubro de 2019, ocorreram as primeiras alterações na cúpula da Secretaria e do Governo. Uma versão do Plano Estratégico estava pronta para ser entregue ao Secretário, quando os principais patrocinadores do projeto saíram abruptamente do Governo. A equipe do 
LAEP foi reduzida em duas pessoas e foi necessário buscar novos aliados para dar continuidade ao principal projeto executado pelo Laboratório em 2019.

A nova liderança da Secretaria de Estado da Casa Civil e Governança decidiu dar continuidade ao trabalho, com pequenas alterações que buscaram destacar as inovações e a conexão com a Agenda 2030 da ONU. Por isso, o LAEP revisitou o Panorama, os OKRs, a consulta pública e evidenciou no documento os principais desafios do Governo conectados ao PPA e aos Objetivos de Desenvolvimento Sustentável. A intenção era que esses desafios públicos norteassem a formulação de políticas públicas e o desenvolvimento de soluções pelo LAEP em 2020, em parceria com os órgãos do Estado.

Como exemplo de desafios, o Plano trazia: alcançar as metas do Ideb no ensino médio e fundamental; diminuir a taxa de mortalidade materna; diminuir a taxa de mortalidade por doenças do aparelho circulatório e transmissíveis; gerar oportunidades de emprego e renda, especialmente para jovens; gerar condições de habitação adequadas para a população; aumentar o percentual da população beneficiada com coleta e tratamento de esgoto; aumentar a distribuição de riquezas; reduzir a taxa de homicídio doloso; diminuir as ocorrências de crime contra o patrimônio; reduzir o número de vítimas de feminicídio; aumentar as receitas do Estado; retornar ao limite legal da dívida estadual; diminuir a pressão da previdência sobre o orçamento.

A pedido da nova cúpula do Governo, o LAEP elaborou uma estratégia de governança do Plano que culminou na criação de um Comitê Estadual de Governança, Inovação e Sustentabilidade (Decreto N ${ }^{o}$ 47.053/2020). Na coordenação do Comitê, estão os órgãos que gerenciam processos transversais de planejamento, orçamento, gestão, arrecadação, controle interno, integridade, inovação e tecnologia, com impacto em toda estrutura de governo. O objetivo do Comitê era acelerar projetos e políticas públicas orientadas para o alcance dos Objetivos de Desenvolvimento Sustentável.

Por fim, já em janeiro e fevereiro de 2020, foram definidos indicadores de resultado conectados ao Plano Plurianual (PPA). Foi produzido um Quadro de Indicadores, com a expectativa de orientar a ação do governo para enfrentar grandes problemas públicos e fornecer um mapa dinâmico das mudanças pretendidas pelo Plano. Em fevereiro de 2020, com a validação do Secretário da Casa Civil e Governança, completava-se o ciclo de elaboração do Plano Estratégico 2025, com orientação de cima para baixo (diretrizes prioritárias dadas pelos dirigentes públicos do Estado - Governador, Vice-Governador e Secretariado), e de baixo para cima (objetivos e resultados-chave idealizados por servidores públicos de médio e alto escalão). Faltaria apenas lançar o Plano e comunicá-lo para a sociedade. O que acabou não acontecendo de forma ampla, por novas mudanças na alta administração do Governo. A seguir, apresentamos as visões de futuro de algumas áreas de governo e exemplos de Objetivos e Resultados Chave criados na área de Desenvolvimento Humano.

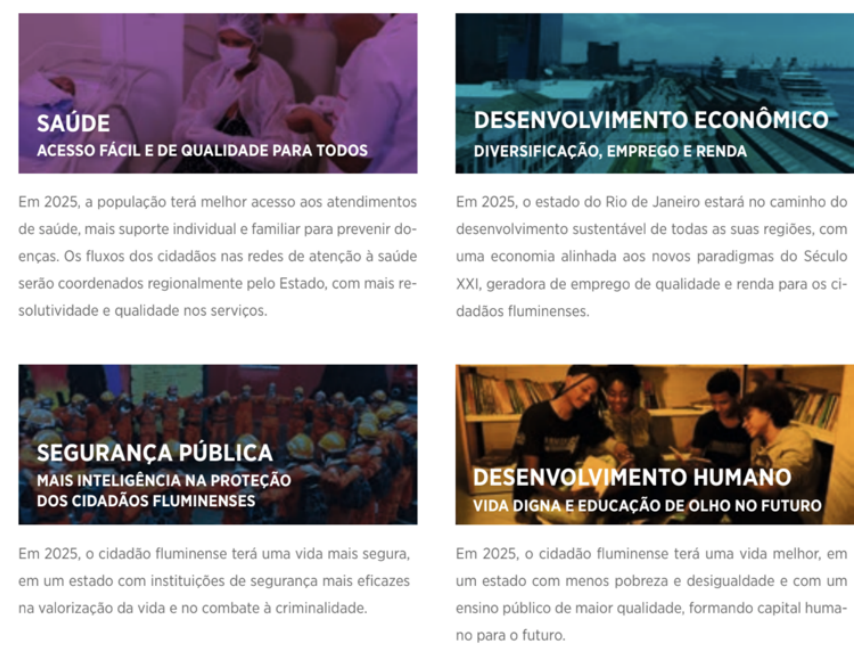

Figura 8 - Visões de futuro de áreas de governo 


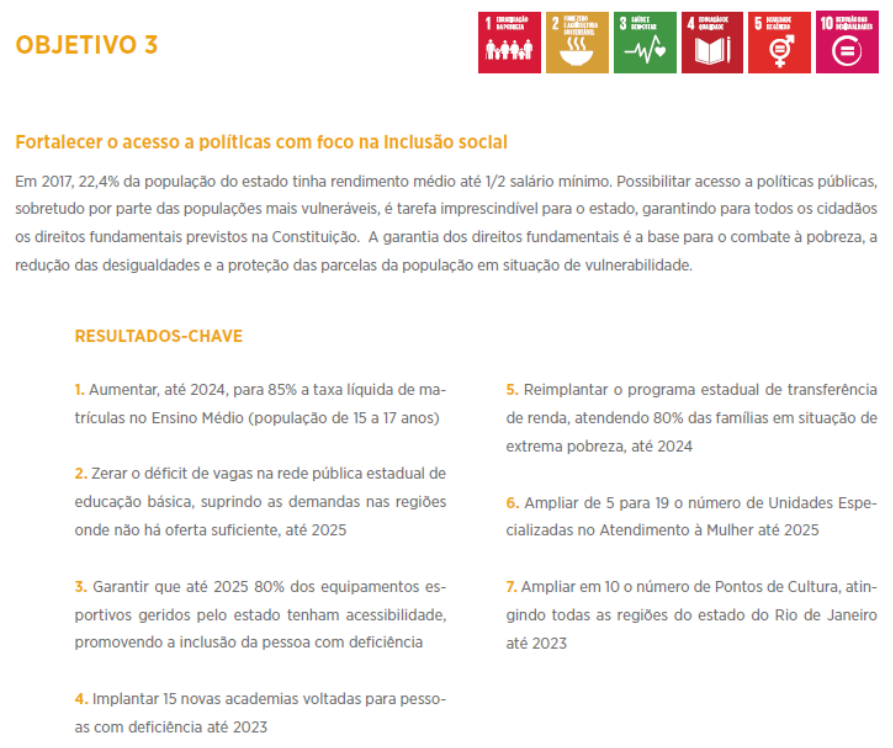

Figura 9 - Objetivos e Resultados Chave da área de Desenvolvimento Humano Fonte: Secretaria de Estado da Casa Civil, 2020.

\section{Considerações finais}

Como mostramos no artigo, o design é aplicável em processos de planejamento e gestão governamental. Abordagens centradas no humano podem contribuir para elevar a cooperação intergovernamental em torno de objetivos comuns de desenvolvimento sustentável. Para isso, é preciso superar grandes desafios da Administração Pública fluminense e estruturais, como a desigualdade social, a alta rotatividade na cúpula do Governo, e a escassez de recursos.

A desigualdade social foi refletida no processo de implementação do Plano Estratégico 2025. Servidores participantes das Oficinas recebiam remunerações diferentes, apesar de ocuparem o mesmo nível hierárquico nas agências que representavam. Além disso, foi notória a ausência de mulheres em cargos mais altos na hierarquia do Governo. O LAEP buscou mitigar esse viés de representatividade no projeto, por meio da ampliação do número de participantes na Rede de Planejamento Estratégico e da realização de uma consulta pública. Mas essas são barreiras superáveis apenas por meio de políticas públicas abrangentes, como ações afirmativas no processo de seleção de profissionais no setor público.

O LAEP priorizou em processos seletivos a entrada de pessoas com deficiência, negras, mulheres, LGBTQIA+. Isso contribuiu para diversificar a equipe ao longo do tempo, mas diferenças na remuneração da equipe do Laboratório com outras unidades de governo permaneceram, dado que o LAEP esteve vinculado a uma Secretaria politicamente prestigiada no Governo, a Casa Civil. Outra alternativa usada pelo LAEP para ampliar a diversidade foi montar grupos de trabalho multisssetoriais em cada projeto ou processo de inovação. Trata-se de estratégia adotada por outros laboratórios de inovação, como o Gnova, o 011Lab (SP), o IrisLab, o LabGes e outros que formam arranjos institucionais voltados para enfrentar problemas públicos.

O desafio da "desigualdade social" foi escolhido pelo LAEP para guiar o desenvolvimento de soluções ao longo de 2019 e 2020. Alguns projetos citados ao longo do artigo demonstram isso, como o "Plano Estadual de Inovação e Tecnologia Educacional" e o "Soluções para a Saúde". Além disso, o LAEP abordou o desafio em diversos eventos de aprendizagem. Na Semana Nacional de Inovação em 2019, realizada em Brasília, por exemplo, o Laboratório facilitou a Oficina "Empatia, Colaboração e Experimentação", com a participação de 
35 servidores públicos de todo o Brasil. Durante 2 horas, os inscritos prototiparam soluções para a desigualdade social, usando ferramentas de design. No final, surgiram protótipos rústicos como um reality show em que famílias do estrato $1 \%$ mais rico viveriam por um mês em famílias de comunidades carentes.
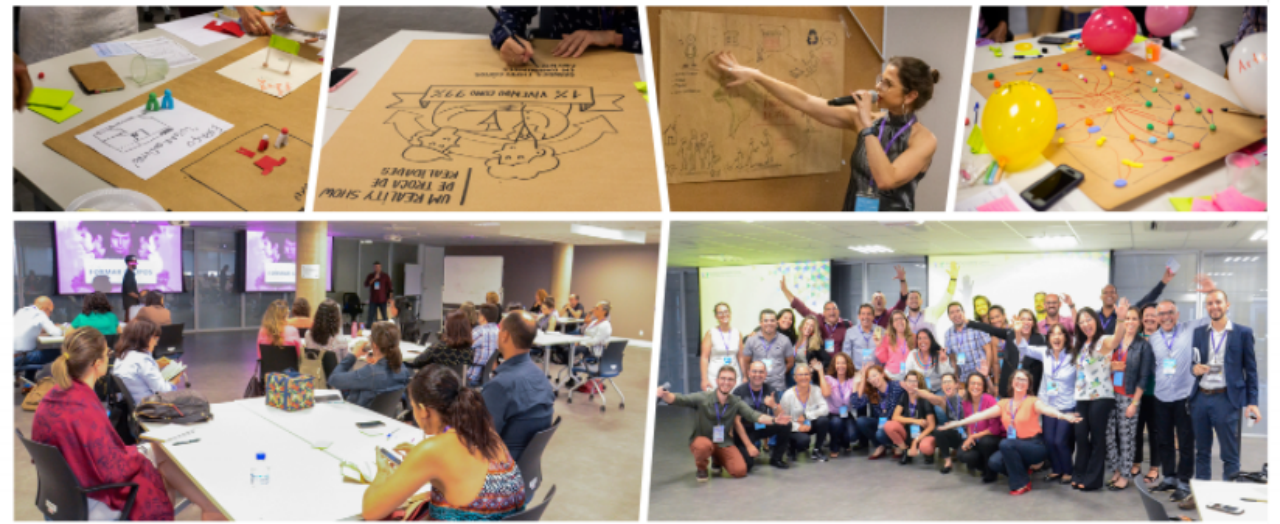

Figura 10 - Oficina de Empatia, Colaboração e Experimentação

Outro grande desafio na implementação do Laboratório foi a frequente mudança na cúpula do Governo e na estrutura administrativa do Estado. Embora esse seja um problema histórico na Administração Pública fluminense, as condições de governabilidade nos anos de existência do LAEP valem estudo aprofundado de cientistas políticos. No início do Governo Witzel, em janeiro de 2019, existiam 19 Secretarias estaduais, cerca de metade ocupada por aliados políticos (PSC, PROS, PSL, PRB). Após romper com o Governo Bolsonaro em setembro de 2019, o PSL deixou de apoiar Witzel, e o Governador criou novas Secretarias e distribuiu cargos para ampliar sua base de apoio na ALERJ. Em junho de 2020, a estrutura do Executivo já possuía 27 Secretarias estaduais, cerca de metade liderada por partidos da coalizão governamental. Com a deflagração da "Operação Placebo" e a abertura do processo de impeachment, porém, o Governo perdeu aliados. Como resultado, três a cada quatro Secretarias mudaram de dirigente em um ano e meio de Governo.

Como manter compromissos e executar metas governamentais, diante de tantas mudanças na agenda política? Eis um desafio comum a todos Laboratórios de Inovação na América Latina, como observaram Ferreira e Botero (2020). O caso da implementação do LAEP é ilustrativo. Além das dificuldades já relatadas para obter a validação do Plano Estratégico 2025, de maio a setembro de 2020 o Laboratório esteve vinculado a três órgãos diferentes. Da Casa Civil passou para a Secretaria de Planejamento e Gestão, em seguida foi para o Centro de Tecnologia de Informação e Comunicação do Estado do Rio de Janeiro (Proderj), onde foi extinto.

Avaliamos que o LAEP deixou legados no serviço público fluminense de práticas experimentais, colaborativas e orientadas para resultados sustentáveis para a população. No caso do Plano Estratégico 2025, a experimentação do design contribuiu para projetar objetivos estratégicos de longo prazo e mapear pontos de interseção na atuação das agências estaduais. Em outros projetos, como o "Guia Presente" e o "Soluções para a Saúde", a abordagem do design possibilitou quebrar problemas complexos em partes menores, envolver usuários e testar protótipos no desenvolvimento de soluções.

Por isso, em contextos altamente ambíguos e conflituosos, argumentamos que Laboratórios de Inovação contribuem para equilibrar a complexidade, estimular a cooperação governamental e a participação social no ciclo de políticas públicas. Mais do que isso, favorecem mudanças institucionais e culturais, ao estimular a experimentação e ampliar repertórios de trabalho de servidores públicos, que relatam ganhar confiança e sentirem-se conectados ao propósito do serviço público durante os processos de design e inovação. 


\section{Referências}

AMPLIFY CHANGE. How to strengthen your organization - strategic planning. Disponível em: https://amplifychangelearn.org/\#en/strengthen/strategic-planning-4-tab. Acesso em: 07 de setembro de 2020 .

D. SCHOOL. The Design Thinking Process. Disponível em:

http://dschool.stanford.edu/redesigningtheater/the-design-thinking-process/. Acesso em: 07 de setembro de 2020 .

DESIGN COUNCIL. The Design Process: What is the Double Diamond. Disponível em: https://www.designcouncil.org.uk/news-opinion/design-process-what-double-diamond. Acesso em: 07 de setembro de 2020 .

EL PAÍS. Seis brasileiros concentram a mesma riqueza que a metade da população mais pobre. Disponível em: https://bit.ly/366VxW9. Acesso em: 08 de setembro de 2020.

. Laboratório de Aceleração da Eficiência Pública. Pesquisatona edição LAEP. Disponível em: https://bit.ly/33VAaEa. Acesso em 06 de setembro de 2020.

Laboratório de Aceleração da Efíciência Pública. Relato de uma experiência: aceleração de ideias em contextos de trabalho remoto e pandemia. Disponível em: https://bit.ly/2RRCZ3I. Acesso em 06 de setembro de 2020 .

Laboratório de Aceleração da Eficiência Pública. A inovação no setor público: uma esperança equilibrista Disponível em: https://bit.ly/3kLzMPH. Acesso em 06 de setembro de 2020.

. OCDE. Fostering Innovation in The Public Sector. Editora OECD, Paris, 2017.

BASON, C. (Ed.). Design for policy: design for social responsibility. Aldershot: Gower Publisher, 2014.

BASON, C. Leading Public Design: How managers engage with design to transform public governance. Tese Doutorado. Copenhagen Business School, 2017.

BUIJS, J; MEER, H. Towards a More Realistic Creative Problem Solving Approach. Creativity and Innovation Management. 2009.

CAVALCANTE, P.; CAMÕES, M.; CUNHA, B.; SEVERO, W. (Orgs.). Inovação no Setor Público: teoria, tendências e casos no Brasil. 1 Ed. Brasília: IPEA, v. 1. 2017.

CAVALCANTE, P.; MENDONÇA, L.; BRANDALISE, I. Políticas públicas e design thinking: interações para enfrentar desafios contemporâneos. Brasília: IPEA, 2019.

CALIMAN, Nara; ASSIS, Marília. Laboratório de Inovação na gestão do Governo do Espírito Santo: resultados e aprendizados. In: CAVALCANTE, P (org). Inovação e políticas públicas: superando o mito da ideia. Brasília, Ipea, 2019.

SECCG, Secretaria de Estado da Casa Civil e Governança. Plano Estratégico 2025 do Estado do Rio de Janeiro, 2020.

CEPERJ. Análise dos aspectos sociais da Qualidade de vida da população do Estado do Rio de Janeiro. Rio de Janeiro: CEPERJ, dez. 2018. 
CEPERJ. Cadernos estudos regionais e metropolitanos: o caso da metrópole fluminense. Ano 1. Número 1. Fevereiro de 2019.

CHRISTIANSEN, J.; BUNT, L. Innovating public policy: allowing for social complexity and uncertainty in the design of public outcomes. In: BASON, C. (Ed.). Design for policy: design for social responsibility. Aldershot: Gower Publisher, 2014. p. 41-56.

CLOUTIER, J. “Qu'est-ce que l'innovation sociale?" CRISES (Centre de recherche sur les innovations sociales), n.0314, 2003.

CLP, Centro de Liderança Pública. Ranking de Competitividade dos Estados. 2018.

DOERR, J. Avalie o Que Importa: Como Google, Bono Vox e a Fundação Gates sacudiram o mundo com os OKRs. Tradução Bruno Menezes. Portfolio, 2018.

GOMIDE, A.; PIRES, R. (eds.) Capacidades Estatais e Democracia: arranjos institucionais de políticas públicas. Brasília: Ipea, 2014

HERCULANO, P. A desigualdade vista do topo: a concentração de renda entre os ricos no Brasil, 19262013. Tese de doutoramento, UNB, 2016. Disponível em: https://repositorio.unb.br/handle/10482/22005. Acesso em: 08 de setembro de 2020.

FERREIRA, Maria; BOTERO, Andrea. Experimental Governance? The Emergence of Public Sector Innovation Labs in Latin America. Policy Design and Practice. 2020, p. 150-162.

FIRJAN. Retratos Regionais - Anuário Econômico. 2018. Disponível em:

http://www.firjan.com.br/publicacoes/publicacoesde-economia/retratos-regionais-1.htm

LOTTA, G.S. Teorias e Análises sobre Implementação de Políticas Públicas no Brasil, Brasília: ENAP, 2019.

MOREIRA, Camila da Silva; TESSAROLO, Enzo M. Capacidades estatais, inovação e design: estratégias de laboratórios de inovação. Anais do 10 Seminário de Administração Pública, IDP, 2020.

RITTEL, H.; WEBBER, M. Dilemmas in a general theory of planning. Policy sciences, Vol. 4, n. 2, 1973.

SANO, H. Laboratórios de inovação no setor público: mapeamento e diagnóstico de experiências nacionais. Cadernos ENAP, 2020.

SARAIVA, E. Introdução à teoria da política pública. In: SARAVIA; FERRAREZI (orgs.). Políticas Públicas. Brasília: ENAP, vol. 1, pp. 21-42, 2007.

SENGE, P.M. The Fifth Discipline: The Art \& Practice of The Learning Organization: Currency Doubleday, New York, 1990.

SEFAZ, Secretaria de Estado de Fazenda do Rio de Janeiro. Relatório de Contas de Governo, 2018.

SILVA, Lucas A. L da. Mecanismos da construção federal da intersetorialidade no Programa Bolsa Família: o papel das burocracias. Revista do Serviço Público. Brasília 64 (3): 327-350 jul/set 2013. 
SORENSEN, E. Governance and Innovation in the Public Sector. In D. Levi-Faur, ed. The Oxford Handbook of Governance. Oxford: Oxford University Press, 2012.

SOUZA, P. H. G. F. de. A desigualdade vista do topo: a concentração de renda entre os ricos no Brasil, 1926-2013. 2016. 378 f. Tese (Doutorado em Sociologia) - Departamento de Sociologia, Universidade de Brasília (UnB). Brasília, 2016.

THALER, Richard H. SUNSTEIN, Cass R. Nudge: como tomar melhores decisões sobre saúde, dinheiro e felicidade. tradução: Ângelo Lessa. Rio de Janeiro: Objetiva, 2019.

TESSAROLO, Enzo Mayer; RODRIGUES, Viviane M. A emergência do modelo quadripartite de proteção, assistência e integração dos refugiados no Brasil. Teoria \& Sociedade nº 20.1, 2012.

TESSAROLO, Enzo Mayer. Capacidades estatais para enfrentar a pobreza: uma análise da implementação estadual de programas de transferência de renda condicionada. Tese de doutorado em Ciência Política. Instituto de Estudos Sociais e Políticos. UERJ, 2018.

TONURIST, P.; KATTEL, R.; LEMBER, V. Innovation labs in the public sector: what they are and what they do? Public Management Review, v. 19, n. 10, p. 1-25, 2017.

WERNECK; FERRAREZI; BRANDALISE; VAQUEIRO; BONDUKI. Ciclos de vida de laboratórios de inovação pública. Brasília: Enap, 2020. Disponível em:

https://repositorio.enap.gov.br/bitstream/1/5000/48/ciclos-vida-labs.pdf 